\title{
A brief history of death switches
}

Immortal remains.

\section{David Eagleman}

There is no afterlife, but a version of us lives on nonetheless.

At the beginning of the computer era, people died with passwords in their heads and no one could access their files. When access to these files was critical, companies could grind to a halt. That's when programmers invented death switches.

With a death switch, the computer prompts you for your password once a week to make sure you are still alive. When you don't enter your password for some period of time, the computer deduces you are dead, and your passwords are automatically e-mailed to the secondin-command. Individuals began to use death switches to reveal Swiss bank account numbers to their heirs, to get the last word in an argument, and to confess secrets that were unspeakable during a lifetime.

It soon became appreciated that death switches provided a good opportunity to say goodbye electronically. Instead of sending out passwords, people began programming their computers to send e-mails to their friends announcing their own death. "It appears I'm dead now," the e-mails began. ${ }^{\alpha} \mathrm{I}^{\prime} \mathrm{ll}$ take this as an opportunity to tell you things I've always wanted to express..."

Soon enough, people realized they could program messages to be delivered on dates in the future: ${ }^{\circ} \mathrm{Happy} 87$ th birthday. It's been 22 years since my death. I hope your life is proceeding the way you want it to."

With time, people began to push death switches further. Instead of confessing their death in the e-mails, they pretended they were not dead. Using auto-responder algorithms that cleverly analysed incoming messages, a death switch could generate apologetic excuses to turn down invitations, to send congratulations on a life event, and to claim to be looking forward to a chance to see them again sometime soon.

Today, building a death switch to pretend you are not dead has become an art form. Death switches are programmed to send a fax occasionally, make a transfer between bank accounts, or make an online purchase of the latest novel. The most sophisticated switches reminisce about shared adventures, exchange memories about a good story, swap inside jokes, brag about past feats, summon up lifetimes of experience.

In this way, death switches have estab-

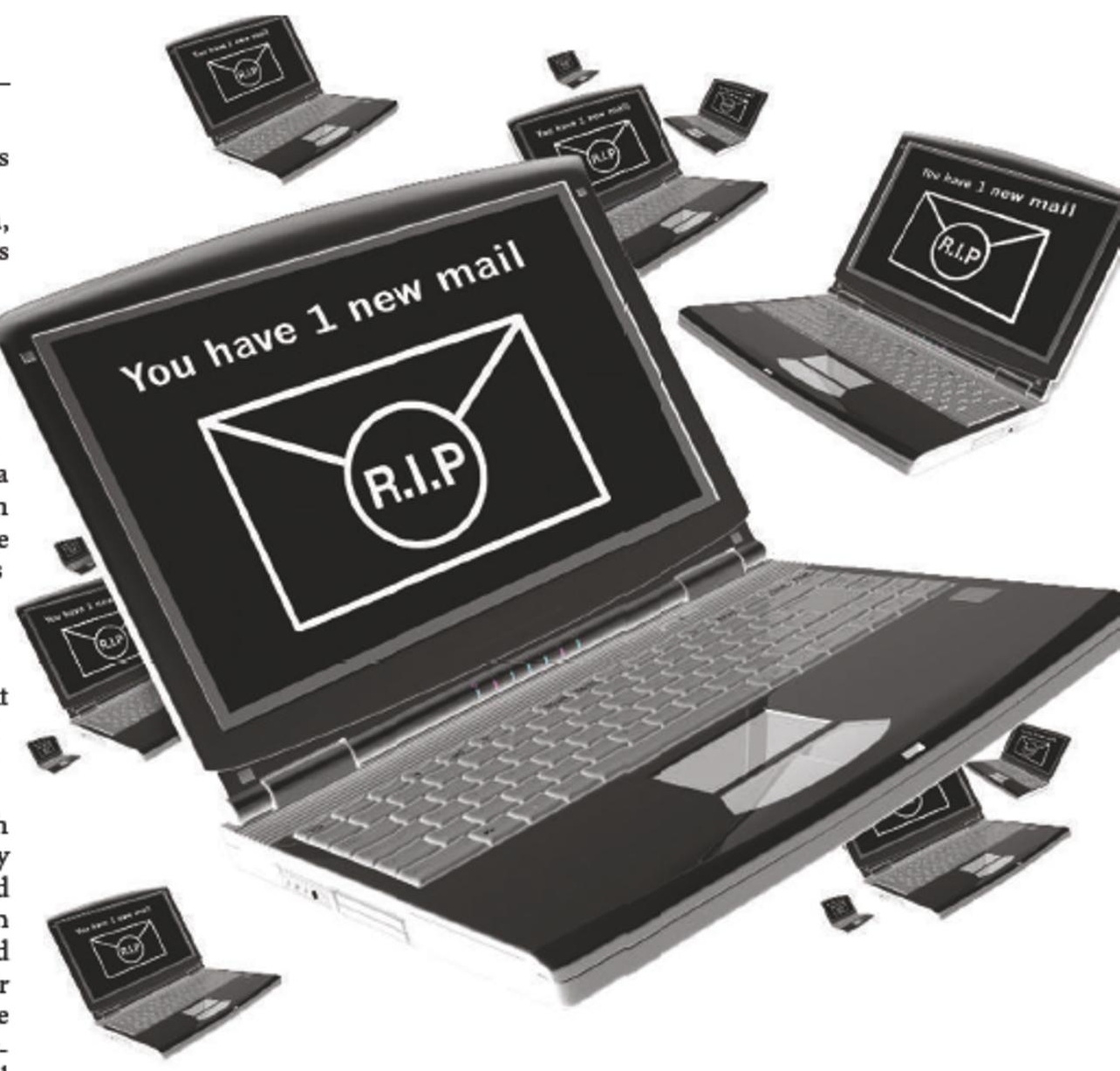

lished themselves as a cosmic joke on mortality. Humans have discovered that they cannot stop Death, but at least they can spit in his drink.

This began as a good-spirited revolution against the grave's silence. The problem for those of us still living, however, is the increasing difficulty in sorting the dead from the living. Computers operate around the clock sending out the social intercourse of the dead: greetings, condolences, invitations, flirtations, excuses, small talk, inside jokes - codes between people who know each other well.

And it is clear now where this society is going. Most people have died off, and I'm one of the few remaining. By the time I die and my own death switch is triggered, there will be nothing left but a sophisticated network of transactions with no one to read them: a society of e-mails zipping back and forth under silent satellites orbiting around a soundless planet.

So an afterlife does not exist for us, per $s e$, but instead an afterlife exists for that which exists between us. When an alien civilization eventually bumps into Earth, it will immediately be able to understand $६$ what humans were about, because what will remain is the network of relationships: who loved whom, who competed, who cheated, who laughed together about road trips and holiday dinners. Each person's ties to bosses, brothers, lovers are written in the electronic communiqués. The death switches simulate the society so completely that the entire social network is reconstructable. The planet's memories survive in zeros and ones.

This situation allows us to forever revisit shared jokes, to remedy lost opportunities for a kind word, to recall stories about delightful earthly experiences that can no longer be felt. Memories now live on their own, and no one forgets them or grows tired of telling them. We are quite satisfied with this arrangement, because reminiscing about our glory days of existence is perhaps all that would have happened in an afterlife anyway.

David Eagleman is a neuroscientist who studies how the brain represents time. He also writes fiction. He can be found at www.eaglemanlab.net. 